\title{
Data Visualization and Analysis of Engineering Educational Statistics
}

\author{
Siddhaling Urolagin, Ishita Upadhyaya, Afrah Abbas Thakur \\ Department of Computer Science, Birla Institute of Technology \& Science, Pilani, Dubai International Academic City, \\ Dubai, United Arab Emirates
}

\begin{tabular}{|c|c|}
\hline Article Info & ABSTRACT \\
\hline & \multirow{8}{*}{$\begin{array}{l}\text { Engineering, is one of the most popular fields of higher education in the } \\
\text { modern day world. Majority of the students these days opt for engineering as } \\
\text { a career, due to the vastness of choices provided by engineering. Mechanical, } \\
\text { Electrical, Computer Science, Civil and Biotechnology are the various } \\
\text { disciplines and have varying strength in terms of number of students who join } \\
\text { a particular discipline. In this research, we have gather data from various } \\
\text { published articles about engineering education and carried out the data } \\
\text { visualization and analysis using Tableau 9.2. The objective of the analysis is } \\
\text { to help the students to make the decision and the choice about discipline of } \\
\text { engineering from which particular university would be the most suitable based } \\
\text { on the data collected and represented. Various categories of statistics such as } \\
\text { number of graduates from a particular university in a particular discipline, and } \\
\text { which university had the maximum number of graduates in a certain year will } \\
\text { help the students make their decisions about their future in a more easy and a } \\
\text { sorted manner. }\end{array}$} \\
\hline Received Mei 12, 2018 & \\
\hline Revised Jul 2, 2018 & \\
\hline Accepted Aug 12, 2018 & \\
\hline Keyword: & \\
\hline Data Visualization & \\
\hline Engineering Education & \\
\hline Statistical Analysis & \\
\hline
\end{tabular}

Copyright $\left({ }_{0} 2018\right.$ Institute of Advanced Engineering and Science. All rights reserved.

\section{Corresponding Author:}

Siddhaling Urolagin,

Department of Computer Science,

Birla Institute of Technology \& Science, Pilani, Dubai International Academic City

Dubai, United Arab Emirates.

Email: siddhaling@dubai.bits-pilani.ac.in

\section{INTRODUCTION}

A term which covers several industries and applications broadly is known as "Engineering". The three fields namely Science, Mathematics and Technology merge together to provide solutions to real-world issues in the form of "Engineering". Engineering educates students and helps them to develop and making those successful engineers through technical expertise, social awareness and innovation [1]. Among all the professions in the world, Engineering is one of the preferred higher education choice by many students [2]. Due to the increase in number of engineering students, the number of graduates from those universities has been rising annually since 2007. According to a research, a large percentage increase in the enrollment of Computer Science and Electrical Engineering [3] has been seen in the universities all-round the globe [4]. The higher education helps students to have a variety of career options to select and be successful engineers [5]. The Universities are considered to be good on the basis of their quality of education, quality of faculty, research output and per capita performance. In this paper, an effort has been made to analyze the data corresponding to engineering universities such number of candidates taking admission, prospective employments by graduates, number of candidates successfully completing graduation etc. A comparison between different branches of engineering disciple is carried out. Such an analysis is not only useful for students looking to join engineering universities but to the universities also. Students seeking new admission can come to know current trends and opportunities in various engineering discipline. With the help of data analysis universities can define new branches based on trends and improve various aspects of existing branches. The research work is organized as 
follows; in section 2 various statistics about engineering education are given, section 3 discusses about number of degrees awarded in various disciples. Engineering branch wise statistical analysis is presented in section 4 . In section 5, analysis on female graduated students given and in section 6 salaries of various engineering branches is presented. The section 7 covers conclusion.

\section{ENGINEERING EDUCATION}

Engineering has some of the major disciplines such as Mechanical, Electrical, Chemical, Biomedical, Computer Science etc., [6] providing solutions to real world problems. Recently several new branches and specializations have evolved showing advancement in modern society. The Computer Science field has been ever evolving since the 1980s [7]. Computer Science has two major fields: Computer Hardware Engineering and Computer Software Engineering. Today, there are several specialties have emerged in field of Computer Science. In the field of Computer Science Engineering, around 4,881 degrees were awarded in U.S. in year 2015. Out of which, $14.8 \%$ of the degree holders were female. University of California, San Diego has handed out the highest number of Computer Science degrees in 2015 with 369 graduates. The number of enrollments in that year was 65,244 [8]. Electrical Engineering deals with designing and working with electrical systems, basic requirements to join Electrical Engineering is to have a strong base in Mathematics and Physics. Based on [9] in $2015,11,385$ degrees were handed out across U.S. in this field and $12.5 \%$ of which were earned by female graduates. University of Illinois had the highest number of Electrical Engineering graduates in 2015. The enrollment number was 102,519 across U.S. Mechanical Engineering has a vast variety of sub branches and this branch is highly focused on practical applications [9]. In 2015, Mechanical Engineering was the branch with the highest number of graduates in the U.S. with an astounding number of 25,436 [8]. Only $13.2 \%$ of these degrees were awarded to women. Maximum number of degrees awarded by Georgia Institute of Technology which of 479 in number. A very high enrollment number is noticed for this branch of engineering in the U.S. alone, with 138,437 students in 2015 [8]. Chemical Engineering mostly deals with the practical applications of chemistry. It involves creating new products with application in pharmaceuticals, cosmetics or the several other fields that involve chemical engineering. In year 2015 around 9,090 Chemical Engineering graduates from the U.S. alone [8]. Ohio State University has awarded the highest number of these degrees and 48,879 students were enrolled into this stream in the U.S. in 2015.

As given in [10][11], Computer Hardware Engineers can expect an average annual salary of $\$ 110,650$ with a median entry level payment of $\$ 66,238$. Job opportunities in this field are expected to rise by $7.4 \%$ by 2022 [10][11]. Software system developers, on the other hand can expect an average annual salary of $\$ 106,050$. The median entry level salary for the same is $\$ 68,510$. Jobs in this field may rise up by $20.4 \%$ [12]. An Electrical Engineer receives an average annual salary of $\$ 97,340$ with a median entry level payment of $\$ 64,981$. Mechanical Engineering graduates can expect a mean annual salary of $\$ 88,190$. The median entry level payment for this field is $\$ 62,527$. Jobs for Mechanical Engineers are expected to rise by $4.5 \%$ by the year 2022 [11]. In the field of Chemical Engineering, one can expect an average annual salary of $\$ 103,960$. The median entry level payment is $\$ 67,006[10]$.

\section{ENGINEERING DEGREES AWARDED}

The Figure 1. depicts the number of bachelor degrees awarded by various disciplines from different U.S universities, with Mechanical discipline awarding highest number of bachelor degrees of 25,436 followed by Civil discipline with 11,900. Computer Science discipline at the fourth place with 10,970 degrees being awarded. In Mining discipline 335 number of bachelor's degree being given. 


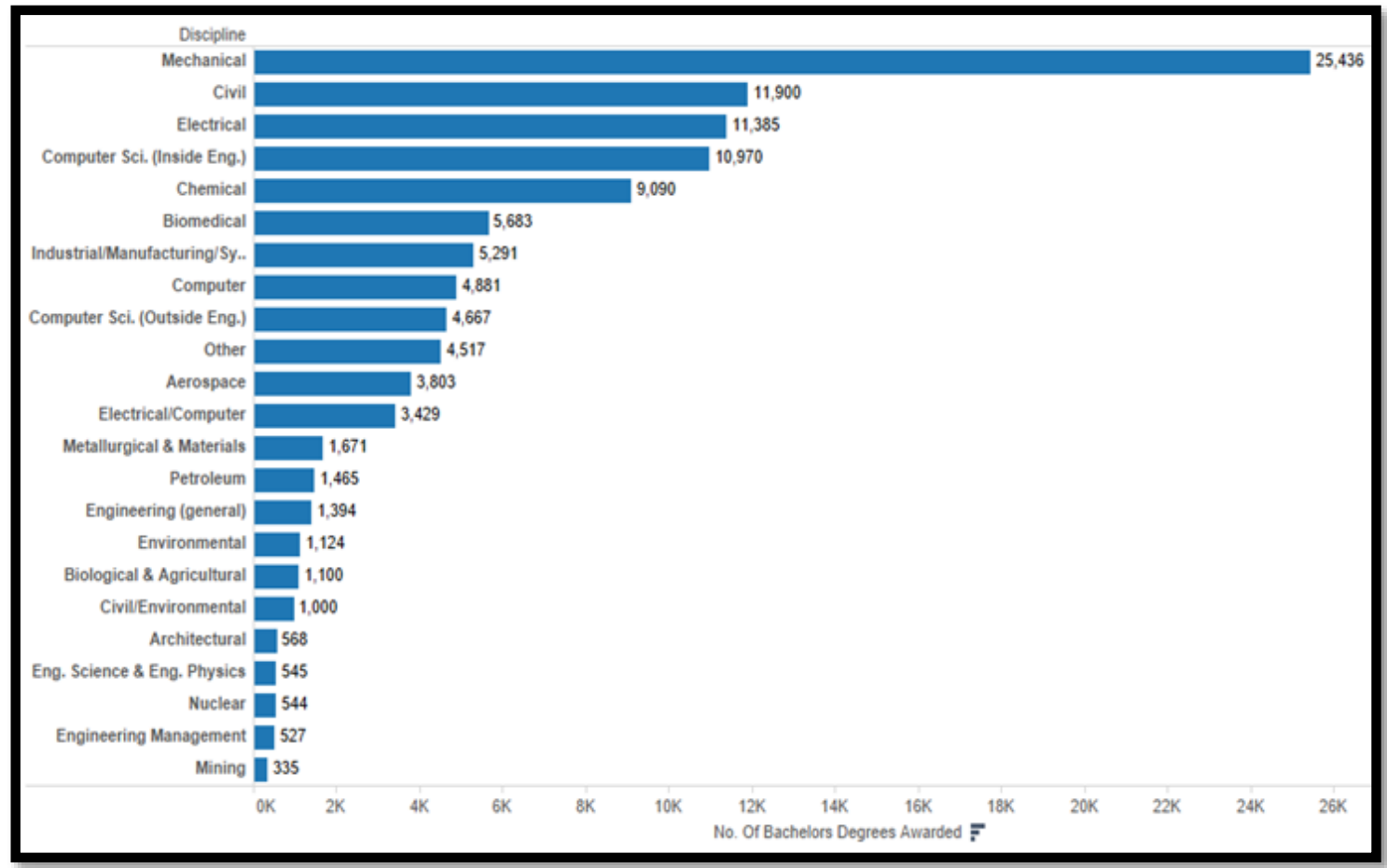

Figure 1. Bachelor's degrees awarded by various disciplines.

The number of degrees awarded in comparison with total number of enrollment across various U.S universities is depicted in Figure 2. Arizona State University has highest number of enrollment of 11,572 and second highest is Texas A\&M University with 10,541 as shown in Figure 2. The number of degrees awarded by Arizona State University is 1,123 and for Texas A\&M University is 1,490. Highest number of degree awarded by University of Illinois with 2,012.

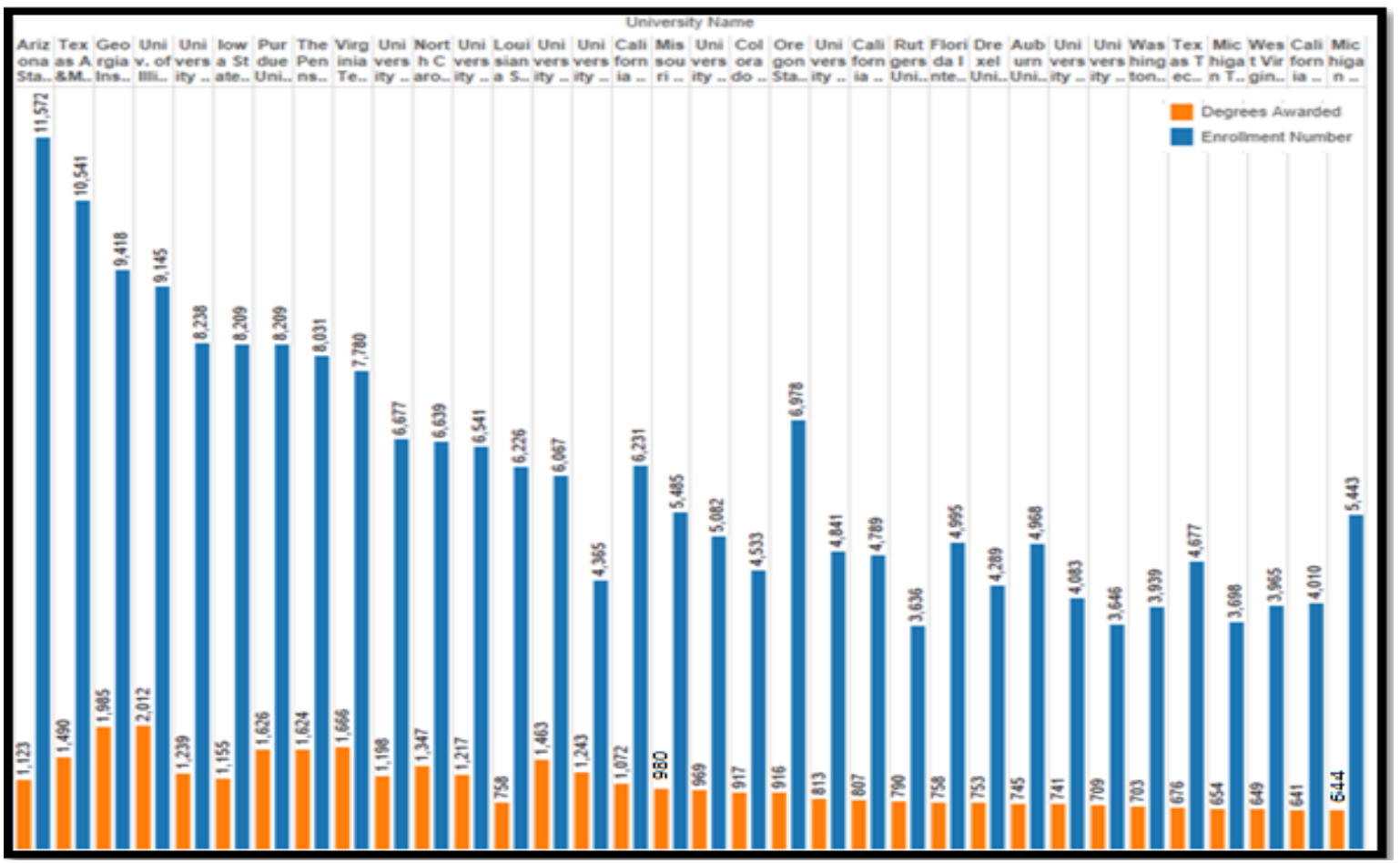

Figure 2. Number of degrees awarded and enrollment number of universities. 


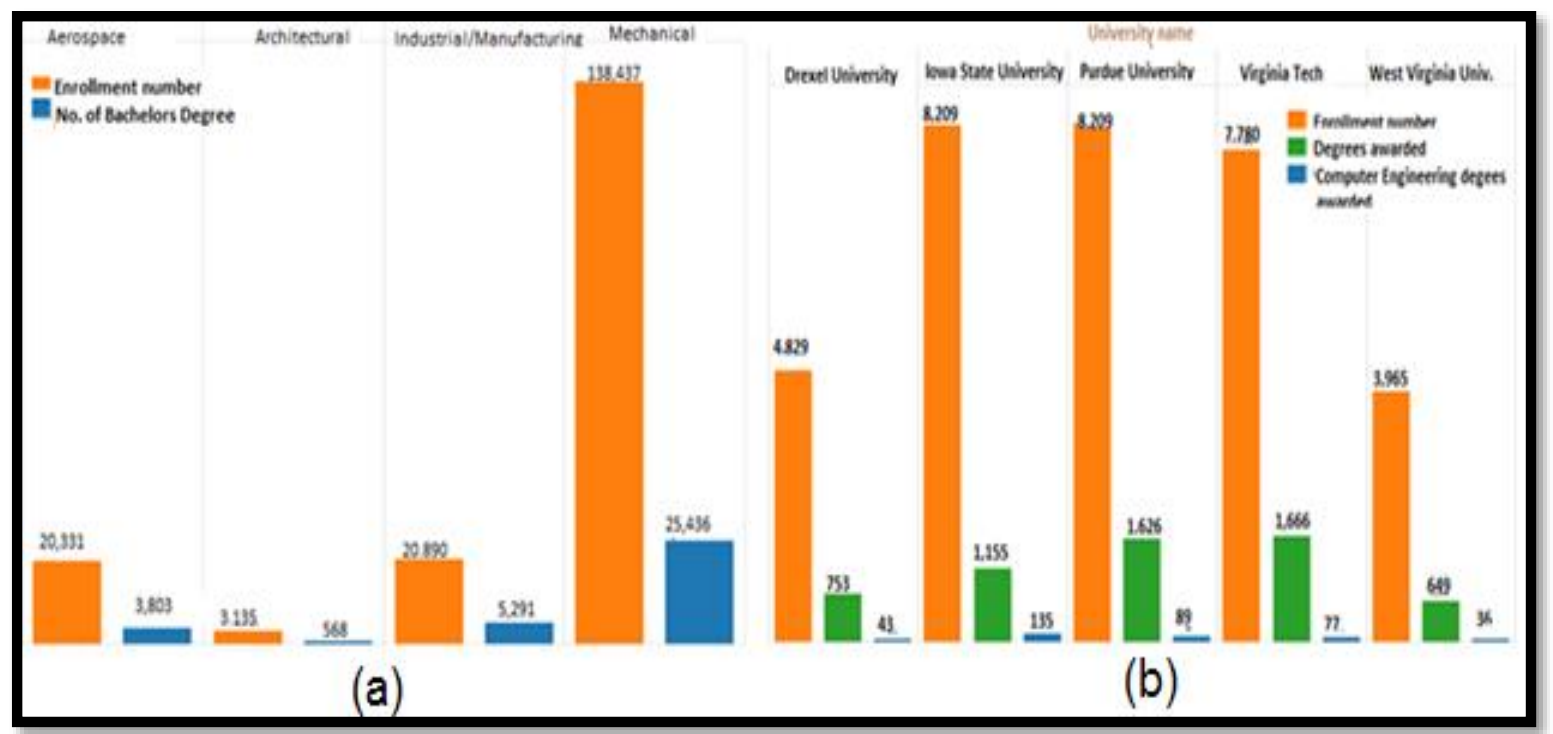

Figure 3(a) Enrollment numbers and degrees awarded by disciplines. (b) Number of enrollment and degree awarded.

In Figure 3(a). Number of students enrolled and number of degree awarded for different engineering disciplines are shown. Mechanical discipline has the highest number of enrollments as 138,437 and the highest number of bachelor degrees being awarded as 25,436 . Aerospace discipline has nearly as much enrollments as Industrial/Manufacturing/Systems discipline, a total of 20,331. Architectural discipline had the lowest enrollments and bachelor degrees being awarded as 3,135 and 568 respectively. The comparison between enrollment and degree awarded in Computer Engineering for Drexel University, Iowa University, Purdue University, Virginia Tech and West Virginia University are show in Figure 3(b). Iowa and Purdue Universities have highest number of enrollment as 8,209 while West Virginia University has lowest as 3,965. While number of bachelor degrees awarded by Purdue is 1,626 and West Virginia as 36 in Computer Engineering.

\section{ENGINEERING BRANCHES}

The number of degree awarded in Mechanical Engineering is depicted using tree map in Figure.4. Georgia Institute of Technology has granted the most number of degrees in the Mechanical Engineering as 479 followed by it Purdue University as 413 . The California State University has awarded lowest number of degrees as 154. The bubbles representation is depicted in Figure. 5(a) and (b). In Figure. 5(a) shows number of degrees awarded in Computer Engineering by various universities. University of California, Berkeley has awarded maximum number of degrees as 283. Number of degrees awarded in Computer Science (outside engineering) is shown in Figure. 5(b) University of California, Irvine followed by University of Texas, Austin have awarded as 343 and 376 respectively. 


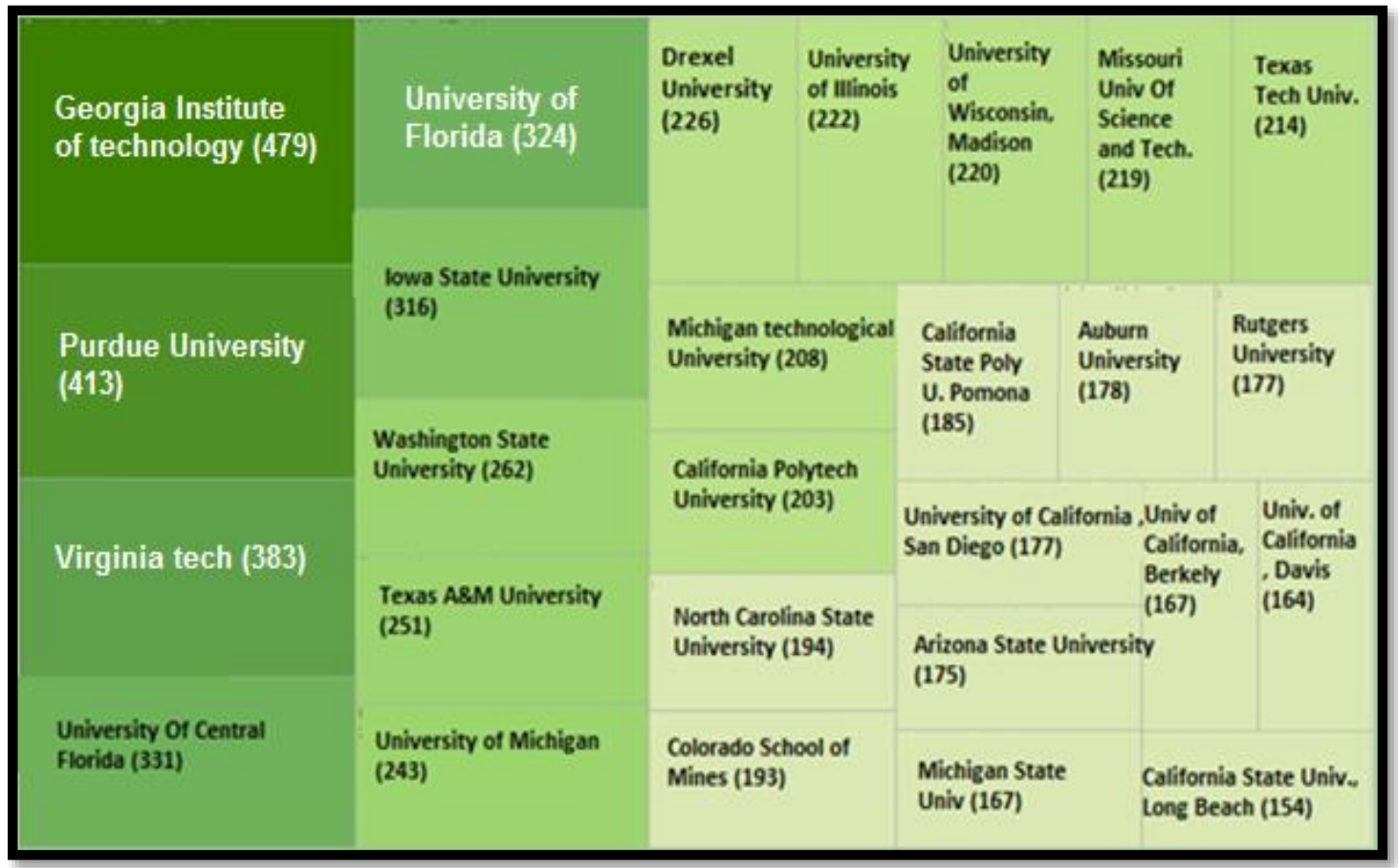

Figure 4. Number of degrees awarded in Mechanical by different universities.

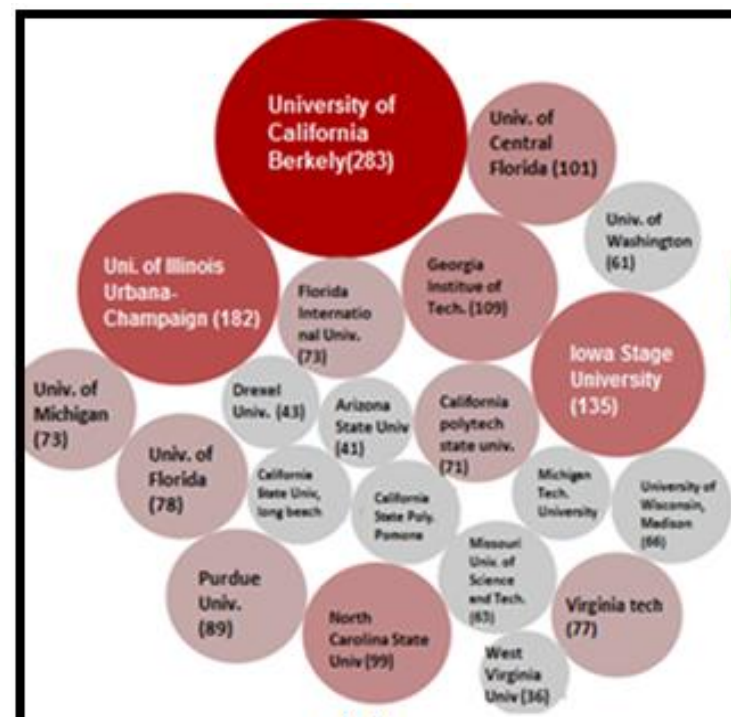

(a)

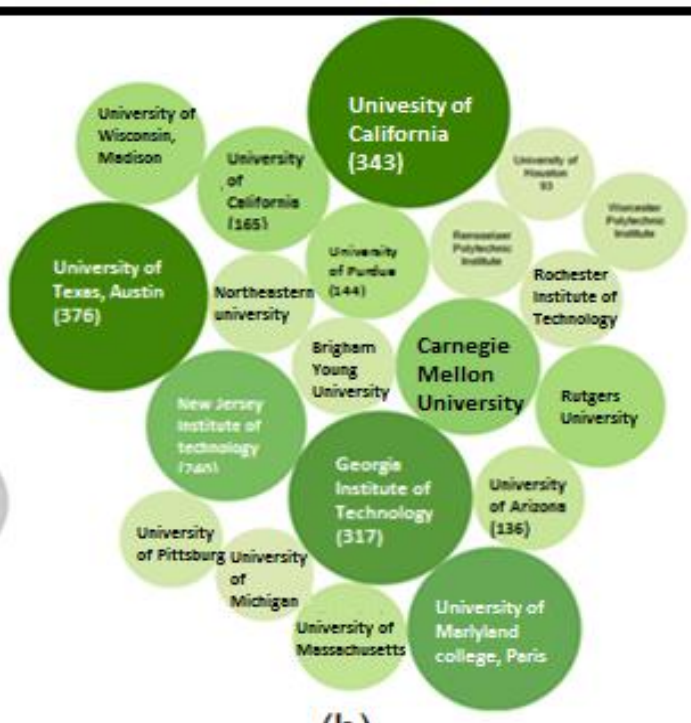

(b)

Figure. 5 (a) Number of degrees awarded by universities in Computer Science. (b) Number of degrees awarded by in Computer Science (outside engineering). 


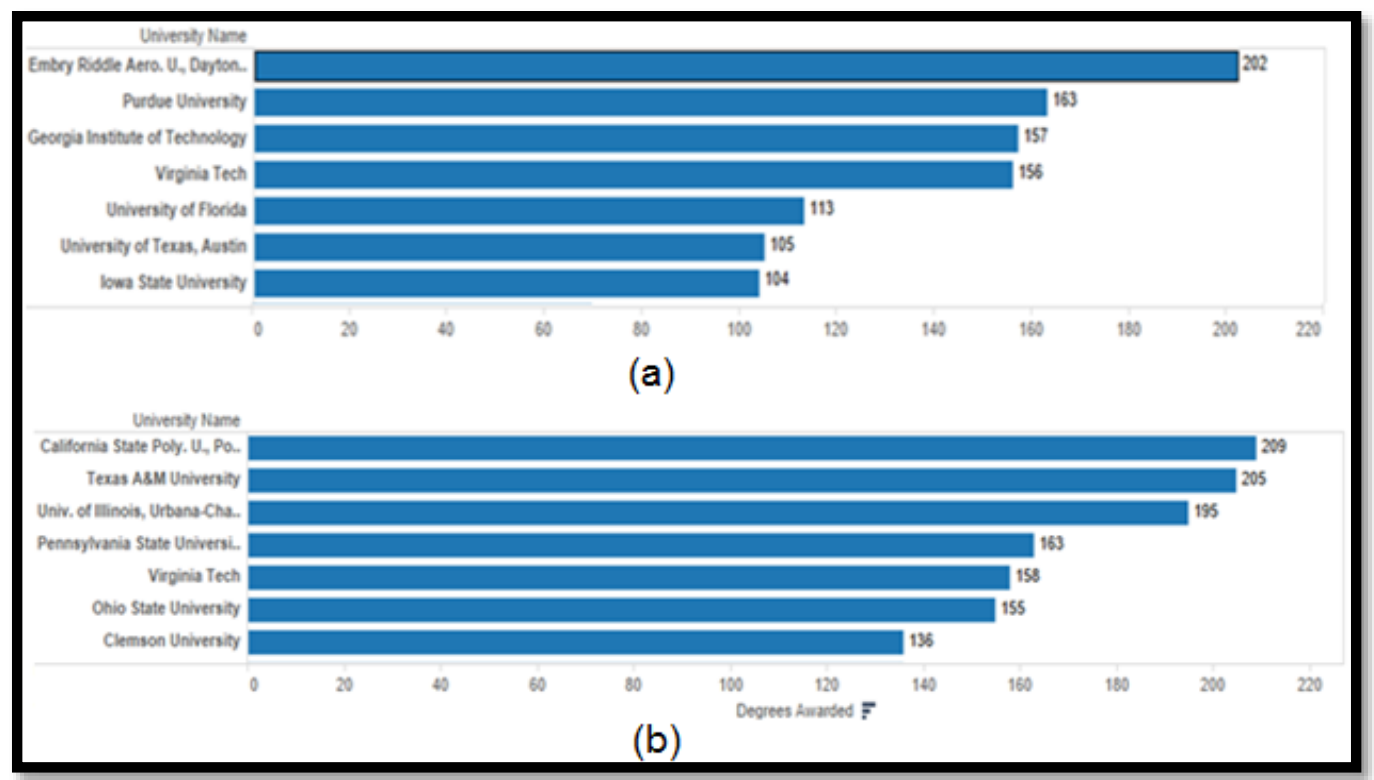

Figure. 6(a) Number of degrees awarded in Aerospace Engineering. (b) Number of degrees awarded in Civil Engineering by various universities.

Highest seven universities based on number of degrees awarded in Aerospace and Civil Engineering are depicted in Figure 6(a) and Figure 6(b). Embry Riddle Aerospace University tops the list with a total of 202 degrees being awarded. The California State Polytechnic University awarding a total of 209 degrees and Texas A\&M University seconds the list by awarding a total number of 205 degrees in Civil Engineering.

\section{FEMALE ENGINEERING STUDENTS}

In Figure. 7 we have analyzed percentage of degrees awarded to women in various engineering disciplines. Biological and Agricultural Engineering percentage of 49.7, which is the highest percentage of degrees awarded to women followed by Biomedical Engineering of percentage $31.2 \%$. The percentage of degree earned by women in Computer Science is $14.8 \%$, in the Mechanical Engineering it is $13.2 \%$.

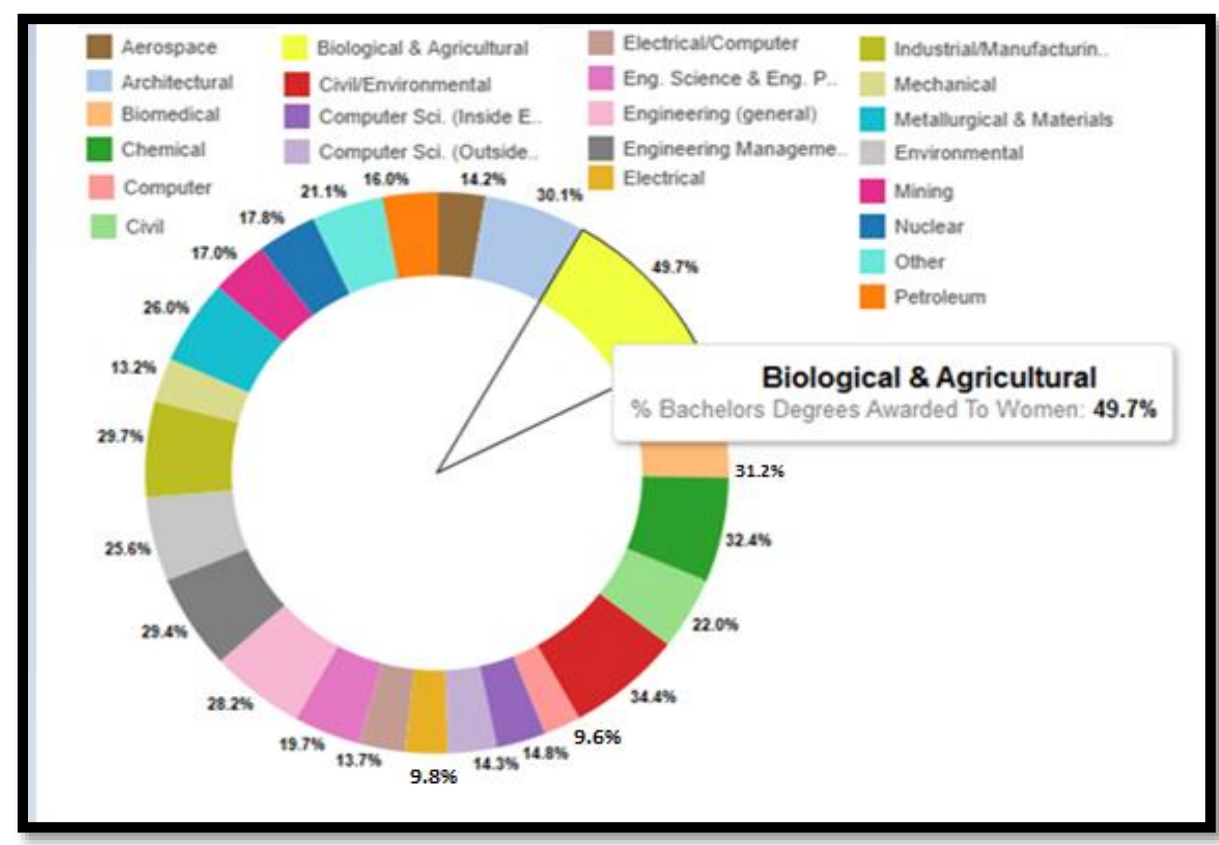

Figure 7. Percentage of degrees awarded in various disciplines for women. 
6. SALARIES

In Figure. 8 a comparison of annual salary for various disciplines is presented. Three main matrices are shown: median entry level salary, mean annual salary and top $10 \%$ of salary in various engineering discipline. Geological and Mining engineering is highest in terms of top10\% salary structure. Based on mean annual salary, Computer Hardware Engineering noted to be highest with \$114970. Mechanical Engineering has mean annual salary of $\$ 88190$.

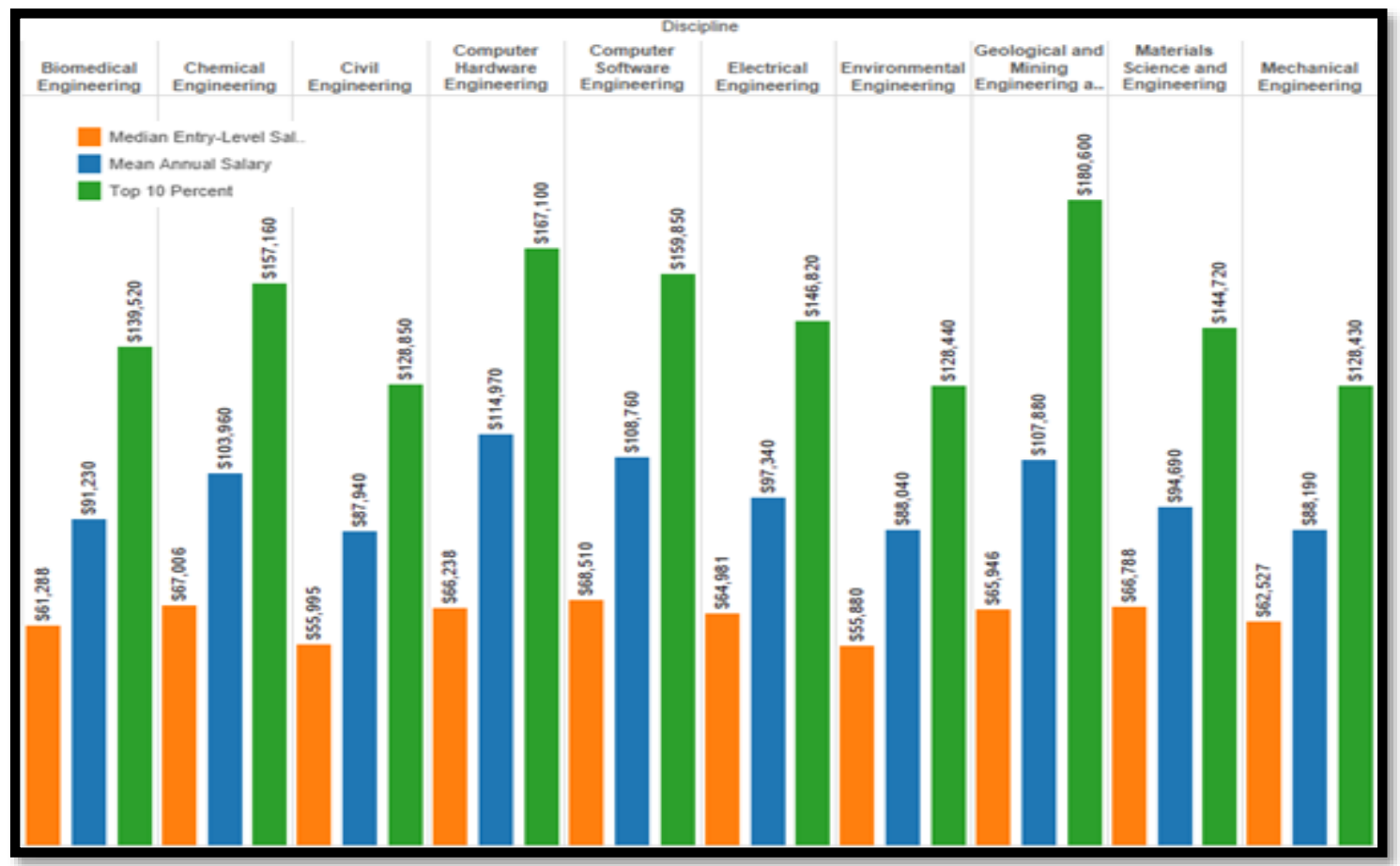

Figure 8. Annual salary for various disciplines.

\section{CONCLUSION}

Based on analysis carried out in this research with the help of Tableau 9.2, Mechanical Engineering has the highest number of degrees awarded and enrollment numbers. Certain engineering branches such as Mining, Environmental Engineering, Engineering Management, Engineering Science, Architectural Engineering and Nuclear Engineering are available in few colleges and have very few students have purse their career. Certain branches of universities are far more successful than their other branches. Some universities have very high enrollment numbers but are lower in rank when it comes to the total number of graduates. For instance Mechanical Engineering has the highest enrollment numbers as well as the highest number of degrees awarded. A large percentage of women opt for Biology related fields such Biological and Agricultural Engineering and Biomedical Engineering. University of Illinois, Urbana-Champaign has the highest total number of degrees awarded and is one of the top most choices of students interested in pursuing engineering. Computer Engineering has been observed to have very high enrollment numbers as well as the highest median entry-level salary and mean annual salary. Based on statistical analysis Computer Science can be seen as very promising field of engineering. Despite having the highest enrollment numbers and number of degrees awarded, Mechanical Engineering is not very rewarding in terms of salary.

In terms of salaries, the Computer Engineering field is very promising for the graduates. Chemical Engineering pays high entry-level salaries as well. Despite very poor enrollment numbers into Geological and Mining Engineering, the top 10 percent of people working in this sector earn the highest salaries when compared to their counterparts in fields such Material Science Engineering, Environmental Engineering, Civil Engineering, Biomedical Engineering. This could probably be because of a high demand and low supply of such engineers. Environmental and Civil Engineers have very low median entry-level salaries compared to other branches 


\section{REFERENCES}

[1] Edward F. Crawley, Johan Malmqvist, Sören Östlund, Doris R. Brodeur, Kristina Edström. "Rethinking engineering education", The CDIO Approach, New York, Springer, 2014.

[2] John Heywood, "Engineering Education", IEEE press Wiley Interscience, 2005.

[3] Mark Guzdial, "Generation CS' Drives Growth in Enrollments", Communications of the ACM, Vol. 60 No. 7, Pages 10-11, 2017.

[4] Heike Jöns, Michael Hoyler, "Global geographies of higher education: The perspective of world university rankings", Geoforum, vol.46, pp 45-59, 2013.

[5] National Science Foundation, Science and Engineering Indicators 2012: Overview, National Science Foundation, Arlington, VA, 2012

[6] Froyd, J.E.; Wankat, P.C.; Smith, K.A., "Five Major Shifts in 100 Years of Engineering Education”, Proceedings of the IEEE. Vol. 100, issue 13, pp. 1344-1360, 2012.

[7] Ceruzzi, Paul E. "A History of a Modern Computing” The MIT Press. 2003.

[8] Yoder, Brian L. "Engineering by the Numbers", In American Society for Engineering Education. 2012.

[9] Dym, C.L.; Agogino, A.M; Eris, O.; Frey, D.D.; Leifer, L.J. , "Engineering Design Thinking, Teaching, and Learning", in Journal of Engineering Education, vol. 94, issue 1, pp. 103-120, 2012.

[10] Engineering Salary Statistics Retrieved from Michigan Technological University, http://www.mtu.edu/engineering/outreach/welcome/salary/, accessed on 5 May, 2017.

[11] The Engineering Income and Salary Survey Standard Report, ASME, 2012.

[12] Dym, C.L., Agogino, A.M, Eris, O., Frey, D.D., Leifer, L.J, "Engineering Design Thinking, Teaching, and Learning", in Journal of Engineering Education, vol. 94, issue 1, pp. 103-120, 2012. 